\title{
13-Deoxytetrodecamycin, a new tetronate ring-containing antibiotic that is active against multidrug-resistant Staphylococcus aureus
}

\author{
Tomas Gverzdys ${ }^{1,3}$, Michael Kamin Hart ${ }^{2,3,4}$, Sheila Pimentel-Elardo ${ }^{1}$, Geoffrey Tranmer ${ }^{2,5}$ and \\ Justin R Nodwell ${ }^{1}$
}

\begin{abstract}
WAC04657 is a wild-isolate Streptomyces that has antibiotic activities against multidrug-resistant Gram-negative and Gram-positive pathogens. From a solid-agar culture of this organism we isolated 13-deoxytetrodecamycin, a novel antibacterial molecule. It is one of at least three distinct antimicrobial compounds produced by this strain. The molecule has the molecular formula $\mathrm{C}_{18} \mathrm{H}_{22} \mathrm{O}_{5}$ and is related to the previously discovered compound tetrodecamycin. 13-Deoxytetrodecamycin has potent bioactivity against Gram-positive pathogens including multidrug-resistant Staphylococcus aureus.
\end{abstract}

The Journal of Antibiotics (2015) 68, 698-702; doi:10.1038/ja.2015.60; published online 27 May 2015

\section{INTRODUCTION}

New antibiotics are needed to combat the increasing prevalence of antibiotic-resistant pathogens. Most of the existing antibiotics are derived from the secondary metabolites of Streptomyces and other environmental microorganisms. The technology for identifying antibiotics from this source, developed during the 25 years following the discovery of streptomycin, focused on testing culture supernatants for their ability to inhibit the growth of target organisms like Staphylococcus aureus and Mycobacterium tuberculosis. ${ }^{1}$ There is now considerable evidence that this technology suffers from a high probability of re-discovering known compounds., ${ }^{2,3}$ The diminishing returns on antibiotic discovery programs were interpreted to mean that most antibiotics produced by Streptomyces had been discovered.

The sequencing of streptomycete genomes suggests that this interpretation was misleading and that this genus has the capacity to provide additional antibacterial compounds having possible clinical utility. ${ }^{4-7}$ The genomes of most Streptomyces species encode genes for 20-50 distinct secondary metabolites, yet the established screening strategies typically reveal 1 or 2 compounds per strain at most. It is not clear whether the 'cryptic' secondary metabolic genes are not expressed in the laboratory or whether they code for bioactive compounds having other functions. For example, some are likely to be siderophores ${ }^{8,9}$ or signaling molecules. ${ }^{10}$ It is clear, however, that at least some of them code for antibiotics. Efforts to activate secondary metabolic genes have revealed rare, overlooked and, in some cases, novel antimicrobials thus underscoring the importance of studying this secondary metabolic 'dark matter'. ${ }^{11-13}$

Additional approaches ${ }^{14,15}$ to finding new bioactive chemical matter involve exploring actinobacteria from novel ecological niches, ${ }^{16-19}$ screening unculturable bacteria (for example, teixobactin) ${ }^{20}$ and screening for new biological activities, such as the inhibition of antibiotic resistance (for example, aspergillomarasmine A). ${ }^{21}$ There is also considerable value in naturally-occurring congeners of known compounds. For example, efforts to identify new vancomycin analogs by mining resistant actinomycetes (pekiskomycin) ${ }^{22}$ and targeted probing of environmental DNA metagenomic libraries (arimetamycin A ${ }^{23}$ have revealed compounds with greater antibacterial activity or reduced potential for activating resistance genes than the parent molecule.

In this work, our approach has been to prioritize an environmental strain of Streptomyces for investigation on the basis of bioactivity against antibiotic-resistant pathogens. Preliminary co-culturing experiments indicated that the strain had the capacity to inhibit the growth of resistant Gram-positive bacteria including multi drug-resistant S. aureus (MRSA) and, under some conditions, Gram-negative bacteria like Acinetobacter baumannii. We report here that this bacterium produces at least three antibacterial activities. We show that one of these molecules, which we have called 13-deoxytetrodecamycin (Figure 1), is a new congener of the tetrodecamycin family $y^{24-26}$ and accounts for some of the bioactivity against several drug-resistant Gram-positive pathogens including MRSA.

${ }^{1}$ Department of Biochemistry, University of Toronto, Toronto, Ontario, Canada and ${ }^{2}$ Department of Biochemistry and Biomedical Sciences, McMaster University, Hamilton, Ontario, Canada

${ }^{3}$ These authors contributed equally to this work.

${ }^{4} 13-$ Deoxytetrodecamycin was first discovered by Michael Kamin Hart (1985-2011). Michael was an outstanding scientist, Leafs fan and a loyal friend. We dedicate our ongoing efforts to his memory.

${ }^{5}$ Current address: College of Pharmacy, University of Manitoba. 750 McDermot Avenue, Winnipeg, Manitoba, Canada R3E 0T5

Correspondence: Professor JR Nodwell, Department of Biochemistry, University of Toronto, 1 Kingâs College Circle, Toronto, Ontario, Canada M5S 1A8.

E-mail: justin.nodwell@utoronto.ca

Received 24 February 2015; revised 13 April 2015; accepted 17 April 2015; published online 27 May 2015 
(1)<smiles>C=C1OC(=O)C2=C1O[C@H]1[C@@H](O)[C@H](O)[C@H]3CCCC[C@H]3[C@H]21</smiles>

(2)<smiles>C=C1OC(=O)C2=C1O[C@H]1[C@@H](C2=O)[C@H](O)[C@]2(O)CCCC[C@H]2[C@H]1O</smiles>

Figure 1 Chemical structure of 13-deoxytetrodecamycin (1) and tetrodecamycin (2).

\section{MATERIALS AND METHODS}

\section{General experimental procedures}

High-resolution mass spectra were measured using an Acquity UPLC-Xevo G2S QTof (Waters, Mississauga, Ontario, Canada). UV/visible spectra were recorded with a DU-530 Spectrophotometer (Beckman, Mississauga, Ontario, Canada). Optical rotation was measured on an Autopol IV automatic polarimeter (Rudolph Research Analytical, Hackettstown, NJ, USA). 1D and 2D NMR data were acquired on an Avance III $700 \mathrm{MHz}$ NMR spectrometer (Bruker, Madison, WI, USA) equipped with a 5-mm QNP cryoprobe operating at $700.17 \mathrm{MHz}$ for ${ }^{1} \mathrm{H}$ NMR and $176.08 \mathrm{MHz}$ for ${ }^{13} \mathrm{C}$ NMR.

\section{Bacterial culture methods}

Streptomyces strain WAC04657 was grown in MYM media at $30^{\circ} \mathrm{C}$ with or without shaking at 200 r.p.m. MYM media is composed of $4 \mathrm{~g} \mathrm{D}-(+)$-maltose monohydrate, $4 \mathrm{~g}$ yeast extract, $10 \mathrm{~g}$ malt extract and $2 \mathrm{ml}$ trace elements ${ }^{27}$ either with or without $20 \mathrm{~g}$ agar in 11 of 1:1 tap water:distilled water. Spore stocks of WAC04657 were made as reported for other Streptomyces. ${ }^{27}$ All other bacterial cultures were grown in $\mathrm{LB}$ broth at $37^{\circ} \mathrm{C}$ with shaking at 200 r.p.m.

\section{Colony diffusion assays}

Petri dishes ( $9 \mathrm{~cm}$ diameter) with $25 \mathrm{ml}$ of MYM agar were spotted with $10^{5}$ CFU of WAC04657 suspended in $5 \mu \mathrm{l}$ of $0.85 \%$ saline and dried under laminar air flow. Plates were incubated for $48 \mathrm{~h}$ and overlaid with $5 \mathrm{ml}$ molten, extra-soft LB agar (2.5 g agar in $11 \mathrm{LB}$ broth) containing $0.5 \%(\mathrm{v} / \mathrm{v})$ of indicator organism from overnight culture. Plates were incubated at $37^{\circ} \mathrm{C}$ overnight and zones of clearance were measured from the edge of the Streptomyces colony to the edge of the zone of clearance.

\section{Phylogenetic tree}

To isolate chromosomal DNA, a $250-\mathrm{ml}$ baffled flask with $25 \mathrm{ml}$ of MYM broth and $2.5 \mathrm{ml}$ of $10 \%$ glycine was inoculated with WAC04657 spores and incubated for $12 \mathrm{~h}$ in a shaking incubator. The cells were collected by centrifugation at $3000 \times \mathrm{g}$ for $10 \mathrm{~min}$ and all but $3 \mathrm{ml}$ of the supernatant was removed. The loose pellet was suspended in the remaining fluid and aliquots were iteratively pelleted in a microcentrifuge at $16000 \times \mathrm{g}$ for $1 \mathrm{~min}$ until all supernatant had been removed. DNA was then extracted from the cells with the DNeasy Blood and Tissue kit (Qiagen) using the 'Pretreatment for Gram-Positive Bacteria' protocol provided by the manufacturer. 16s rDNA was sequenced using the primers AGAGTTTGATCCTGGCTCAG and ACGGCTACCTTGTTACGACTT resulting in a sequence of $1335 \mathrm{bp}$ after

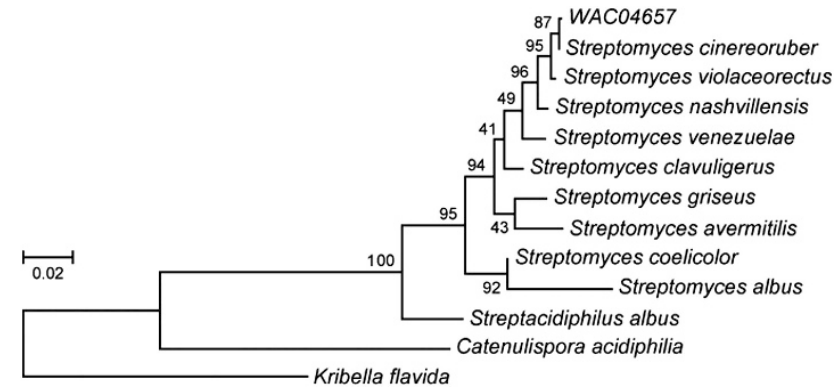

Figure 2 Phylogenetic tree based on 16S rDNA sequences shows that WAC04657 clusters within the genus Streptomyces and not in the closely related genera of Streptacidiphilus or Catenulispora. Kribella flavida was used as an outgroup.

trimming. 16S rDNA sequences from other organisms were obtained by performing a blastn search of the NCBI databases with the WAC04657 rDNA sequence as the query. The resulting sequences were aligned with MUSCLE ${ }^{28}$, trimmed and used in MEGA6 ${ }^{29}$ to build the phylogenetic tree (parameters: model T92+G+I, ML tree, 500 bootstrap replicates).

\section{TLC, bioautography and HPLC analysis}

The crude extract was dissolved in chloroform to $4 \mathrm{mg} \mathrm{ml}^{-1}$ and $10 \mu \mathrm{l}$ was spotted on a silica TLC plate. The TLC plate was developed in 1:9 methanol: chloroform and visualized by UV at $254 \mathrm{~nm}$ or by bioautography. Bioautography was performed by overlaying the TLC plates with extra-soft LB agar mixed with a $0.5 \%(\mathrm{v} / \mathrm{v})$ culture of $B$. subtilis 168 . Plates were incubated overnight at $37^{\circ} \mathrm{C}$, sprayed with thiazolyl blue tetrazolium bromide dye (MTT; $5 \mathrm{mg} \mathrm{ml}^{-1}$ in $\mathrm{H}_{2} \mathrm{O}$ ), and incubated for $1 \mathrm{~h}$ at $37^{\circ} \mathrm{C}$ before visualizing. From a TLC plate run in parallel, the band of silica gel corresponding to the zone of activity was scraped off the aluminum backing and extracted with chloroform. The resulting extract was dried under vacuum, suspended in DMSO, and subjected to HPLC with $\mathrm{H}_{2} \mathrm{O}$ (solvent A) and acetonitrile (solvent B) mobile phases on an XSELECT CSH C18, $5 \mu \mathrm{m}, 4.6 \times 150 \mathrm{~mm}$ column (Waters) as follows: $1 \mathrm{ml} \mathrm{min}^{-1}, 35^{\circ} \mathrm{C} ; 0.0 \mathrm{~min}, 20 \% \mathrm{~B} ; 3.0 \mathrm{~min}, 40 \% \mathrm{~B} ; 8.0 \mathrm{~min}, 40 \% \mathrm{~B}$; 8.5 min, $95 \%$ B; 10.5 min, $95 \%$ B; 11.0 min, $20 \%$ B; 13.5 min, $20 \%$ B.

\section{Purification of 13-deoxytetrodecamycin}

Four hundred milliliters of MYM agar was poured into $24 \times 32 \mathrm{~cm}$ dishes, inoculated with $\sim 6 \times 10^{7} \mathrm{CFU}$ and incubated for 5 days. The agar and cell mat was macerated and extracted with an equal volume of ethyl acetate overnight. The extract was gravity filtered, dried in a rotary evaporator under vacuum, dissolved in $2 \mathrm{ml}$ of $50 \%$ aqueous acetonitrile and loaded onto a $5 \mathrm{~g}$ Sep-Pak $\mathrm{C} 18$ column (Waters). The column was washed with $10 \mathrm{ml}$ of $\mathrm{H}_{2} \mathrm{O}$ and $10 \mathrm{ml}$ of $30 \%$ aqueous acetonitrile. 13-Deoxytetrodecamycin was eluted with $70 \%$ aqueous acetonitrile and dried by lyophilization. The 13-deoxytetrodecamycin fraction was then suspended in $50 \%$ aqueous acetonitrile, washed with hexane and subjected to an initial round of HPLC purification as described above while monitoring at $271 \mathrm{~nm}$. 13-Deoxytetrodecamycin eluted at approx. $8.0 \mathrm{~min}$. The molecule was dried by lyophilization and further separated by HPLC on a XSELECT CSH Fluoro-Phenyl, $5 \mu \mathrm{m}, 4.6 \times 150 \mathrm{~mm}$ column (Waters) with $\mathrm{H}_{2} \mathrm{O}$ (solvent A) and acetonitrile (solvent B) as the mobile phases with the following method: $1 \mathrm{ml} \mathrm{min}^{-1}, 35^{\circ} \mathrm{C} ; 0 \mathrm{~min}, 20 \% \mathrm{~B} ; 3 \mathrm{~min}, 40 \% \mathrm{~B} ; 7 \mathrm{~min}$, $40 \% \mathrm{~B} ; 7.5 \mathrm{~min}, 20 \% \mathrm{~B} ; 9.5 \mathrm{~min}, 20 \%$ B. 13-Deoxytetrodecamycin eluted at $6.75 \mathrm{~min}$. The molecule was dried by lyophilization, extracted with chloroform and dried under vacuum to yield pure 13-deoxytetrodecamycin.

\section{Minimum inhibitory concentration}

LB agar was melted and cooled to $55^{\circ} \mathrm{C}$. Twofold dilutions of molecule from $64 \mu \mathrm{g} \mathrm{ml}^{-1}$ to $1 \mu \mathrm{g} \mathrm{ml}^{-1}$ were added to the molten agar and poured into petri dishes. Overnight cultures of each indicator organisms were diluted to $\mathrm{OD}_{600}$ 0.001 , and $5 \mu \mathrm{l}$ was spotted onto the antibiotic plates and allowed to dry. Plates were incubated for $16 \mathrm{~h}$ at $37^{\circ} \mathrm{C}$. The MIC was defined as minimum 
concentration of molecule at which no growth of the indicator organism could be visually detected.

\section{RESULTS}

Identification of an anti-MRSA activity

WAC04657 is a bacterium of the genus Streptomyces (Figure 2) from the Wright Actinomycete Collection (wac.mcmasteriidr.ca). In the course of genetic engineering experiments aimed at potentiating secondary metabolism, we found that it exhibits potent antibacterial activity against several antibiotic-resistant pathogens. This includes Gram-positive pathogens such as MRSA (Table 1) and, under some conditions, Gram-negative pathogens including highly antibioticresistant strains such as A. baumannii (data not shown).

To identify the compounds associated with these antimicrobial activities, we grew solid agar cultures of the organism, extracted with ethyl acetate, evaporated the extracts to dryness and dissolved the extract in chloroform. As an initial means of identifying these activities, we separated the extracts by TLC, and overlaid the plates with the bacterium Bacillus subtilis. Staining the cells with thiazolyl blue tetrazolium bromide (MTT) revealed three zones of inhibited growth (Figure 3a). The compound showing the greatest activity migrated through the plate with an $\mathrm{R}_{\mathrm{f}}$ of 0.5 . From a TLC plate run in

Table 1 Colony diffusion assays of WAC04657 against Gram-positive bacteria

\begin{tabular}{lc}
\hline Test organism & Zone of clearance $(\mathrm{mm})$ \\
\hline Bacillus subtilis 168 & 4 \\
Micrococcus luteus & 3 \\
Staphylococcus aureus ATCC 29213 & 1.5 \\
S. aureus ATCC BAA-41 & 4 \\
S. aureus ATCC BAA-44 & 5 \\
S. saprophyticus ATCC 15305 & 2 \\
S. epidermidis ATCC 12228 & 2 \\
Enterococcus faecalis ATCC 29212 & 2 \\
\hline
\end{tabular}

Abbreviation: ATCC, American Type Culture Collection.
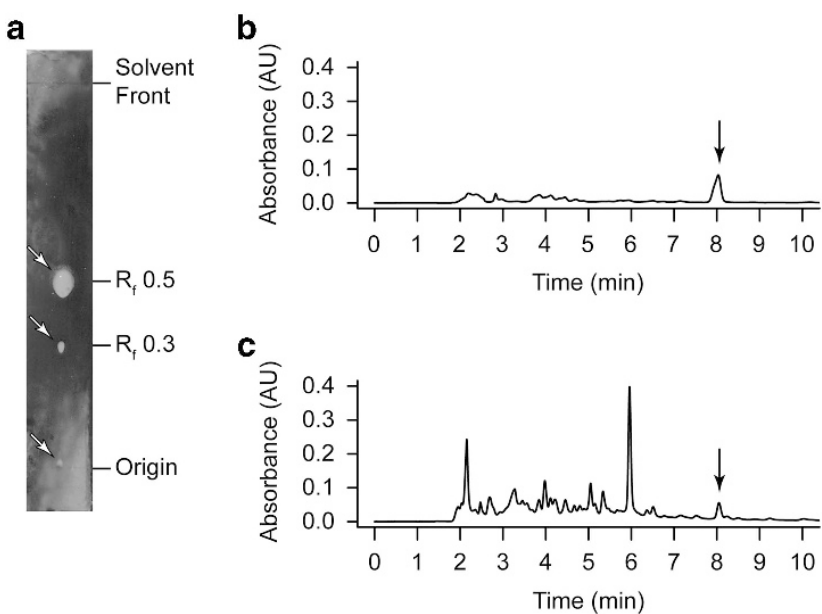

Figure 3 TLC was used to identify the active compound. (a) Crude extract was separated by TLC and the plate was overlaid with $B$. subtilis to visualize the active compounds. The molecule corresponding to $R_{f} 0.5$ was extracted from the silica of a plate run in parallel and visualized by HPLC at $220 \mathrm{~nm}$ (b). This guided purification of the active molecule from the crude extract (c). parallel, we chloroform extracted the band of the silica corresponding to the activity, and subjected the resulting compound to HPLC analysis. The chromatograph revealed that the activity consisted of one primary peak (Figure $3 \mathrm{~b}$ ). This semi-pure product was used to guide method development for HPLC-directed purification of the compound from large-scale crude extracts (Figure 3c).

\section{Large-scale isolation and purification of antibiotic activity}

To isolate the activity in larger quantities, 12.81 of solid agar culture were macerated and extracted with an equal volume of ethyl acetate. The solvent was gravity filtered and dried under vacuum. The resulting oily, brown extract $(663 \mathrm{mg}$ ) was suspended in $2 \mathrm{ml}$ of $50 \%$ aqueous acetonitrile and loaded onto a Sep-Pak C18 column. The column was washed with $10 \mathrm{ml}$ each of $100 \%$ water and $30 \%$ aqueous acetonitrile. The active compound was subsequently eluted with $10 \mathrm{ml}$ of $70 \%$ aqueous acetonitrile, brought to dryness under vacuum in a centrifugal evaporator $(115 \mathrm{mg}$ ) and redissolved in $50 \%$ acetonitrile. After a hexane wash, the resulting material was purified by reversed-phase chromatography on a $\mathrm{C}_{18}$ column and lyophilized to yield a light pink powder $(4 \mathrm{mg})$. This was suspended in DMSO, further purified by reversed-phase chromatography on a PFP column and dried by lyophilization $(1.2 \mathrm{mg})$. The resulting white powder was extracted with chloroform and dried under vacuum to yield pure 13-deoxytetrodecamycin $(1.1 \mathrm{mg})$ as a white residue.

\section{Physicochemical properties and structural elucidation of 13-deoxytetrodecamycin}

The physicochemical properties of 13-deoxytetrodecamycin are summarized in Table 2. The compound exhibited a pseudomolecular ion that corresponded to the molecular formula $\mathrm{C}_{18} \mathrm{H}_{22} \mathrm{O}_{5}$ by high resolution LC-ESI-MS (m/z $341.1365 \quad[\mathrm{M}+\mathrm{Na}]^{+}$; calculated $\mathrm{m} / \mathrm{z}$ $\left.341.1374[\mathrm{M}+\mathrm{Na}]^{+}\right)$indicating eight degrees of unsaturation. The similarity of its molecular formula with tetrodecamycin $\mathrm{C}_{18} \mathrm{H}_{22} \mathrm{O}_{6}$ (Figure 1 ) as well as extensive analysis of the $1 \mathrm{D}\left({ }^{1} \mathrm{H}, \mathrm{DEPTQ}\right)$ and $2 \mathrm{D}$ (HSQC, HSQC-TOCSY, COSY and HMBC) NMR spectra (Table 3, Supplementary Figures S1-S6) suggested that the compound is a new tetrodecamycin derivative. ${ }^{26}$ The main difference is the lack of the hydroxyl group at $\mathrm{C}-13$ of the decalin ring, thus motivating the name 13-deoxytetrodecamycin. The methanetriyl group at C-13 was found at $\delta \mathrm{c} 36.8$ which indicated the lack of hydroxyl group at this position.

Table 2 Physico-chemical properties of 13-deoxytetrodecamycin

\begin{tabular}{|c|c|}
\hline Description & Details \\
\hline Appearance & White residue \\
\hline Molecular formula & $\mathrm{C}_{18} \mathrm{H}_{22} \mathrm{O}_{5}$ \\
\hline Molecular mass $\left(\mathrm{g} \mathrm{mol}^{-1}\right.$ ) & 318 \\
\hline \multicolumn{2}{|l|}{ ESI-MS $(\mathrm{m} / \mathrm{z})$} \\
\hline Found $(\mathrm{M}+\mathrm{Na})^{+}$ & 341.1365 \\
\hline Calculated $(\mathrm{M}+\mathrm{Na})^{+}$ & 341.1374 \\
\hline$[\alpha]_{D}\left(20^{\circ} \mathrm{C}, \mathrm{CHCl}_{3}\right)$ & $-17.6^{\circ}$ (с 0.65) \\
\hline \multicolumn{2}{|l|}{ Solubility } \\
\hline soluble & DMSO, $\mathrm{CHCl}_{3}$ \\
\hline insoluble/poorly soluble & $\begin{array}{l}\text { Water, acetonitrile, methanol, acetone, ethyl acetate, } \\
\text { 2-propanol, } n \text {-hexane }\end{array}$ \\
\hline UV $\lambda_{\max }($ loge $)\left(\mathrm{CHCl}_{3}\right)$ & 272.6 nm (3.96) \\
\hline
\end{tabular}

Abbreviation: DMSO, dimethyl sulfoxide. 
Table $3{ }^{13} \mathrm{C}(176.08 \mathrm{MHz})$ and ${ }^{1} \mathrm{H}$ NMR $(700.17 \mathrm{MHz})$ data of 13-deoxytetrodecamycin in $\mathrm{CDCl}_{3}$

\begin{tabular}{|c|c|c|c|}
\hline Position & $\delta_{C}$ & $\delta_{H}$ & Multiplicity $\left(J_{H-H}\right)$ \\
\hline 1 & 165 & & \\
\hline 2 & 101.3 & & \\
\hline 3 & 164.6 & & \\
\hline 4 & 148.5 & & \\
\hline \multirow[t]{2}{*}{5} & 96.5 & 5.36 & $d(2.7)$ \\
\hline & & 5.26 & $d(2.7)$ \\
\hline 6 & 195 & & \\
\hline 7 & 53.6 & & \\
\hline 8 & 40.9 & 1.23 & $\mathrm{~m}$ \\
\hline \multirow[t]{2}{*}{9} & 25.1 & 1.72 & $\mathrm{~m}$ \\
\hline & & 1.15 & $\mathrm{~m}$ \\
\hline \multirow[t]{2}{*}{10} & 27.3 & 1.57 & $\mathrm{~m}$ \\
\hline & & 1.17 & $\mathrm{~m}$ \\
\hline \multirow[t]{2}{*}{11} & 25.9 & 1.73 & $\mathrm{~m}$ \\
\hline & & 1.05 & $\mathrm{~m}$ \\
\hline \multirow[t]{2}{*}{12} & 32.7 & 2.3 & $\mathrm{~m}$ \\
\hline & & 0.96 & $\operatorname{tdd}(13.2,10.5,3.6)$ \\
\hline 13 & 36.8 & 1.21 & $\mathrm{~m}$ \\
\hline 14 & 79.8 & 3.59 & $d(4.2)$ \\
\hline 15 & 92.1 & 4.75 & $\mathrm{dd}(2.8,1.8)$ \\
\hline 16 & 34.4 & 2.13 & $\mathrm{dq}(7.4,2.9)$ \\
\hline 17 & 16.7 & 1.14 & $\mathrm{~s}$ \\
\hline 18 & 13.7 & 1.02 & $d(7.4)$ \\
\hline
\end{tabular}

This is in contrast to that reported of tetrodecamycin at $\delta \mathrm{c} 69.0$ (C-13) which corresponded to a tertiary alcohol. ${ }^{26}$ The assignment of this methanetriyl group $\left(\delta_{\mathrm{C}} 36.8\right)$ at this position was further supported by COSY and HMBC correlations: $\delta_{\mathrm{H}} 1.21(\mathrm{H}-13)$ to $\delta_{\mathrm{H}} 3.59(\mathrm{H}-14), \delta_{\mathrm{H}}$ $2.30(\mathrm{H}-12), \delta_{\mathrm{H}} 0.96(\mathrm{H}-12)$ and $\delta_{\mathrm{H}} 4.75(\mathrm{H}-15), \delta_{\mathrm{H}} 3.59(\mathrm{H}-14)$ to $\delta_{\mathrm{C}}$ 36.8 (C-13; Supplementary Figures S5 and S6).

Relative stereochemistry of 13-deoxytetrodecamycin was identical to tetrodecamycin from NOESY data (Supplementary Figure S7). Originally, the relative stereochemistry of dihydrotetrodecamycin was first proven by X-ray crystal structure determination, and by analogy, the relative stereochemistry of tetrodecamycin was then proved by chemical conversion of tetrodecamycin into two epimers of dihydrotetrodecamycin, one of which had identical ${ }^{1} \mathrm{H}$ NMR data and specific rotation as dihydrotetrodecamycin. Therefore, the relative stereochemistry of tetrodecamycin was concluded to be the same as dihydrotetrodecamycin. ${ }^{26}$ A close inspection of the original ${ }^{1} \mathrm{H}$ NMR of dihydrotetrodecamycin describes a coupling constant of 3.4 between $\mathrm{H}-16$ and $\mathrm{H}-15\left(J_{\mathrm{H} 16, \mathrm{H} 15}=3.4 \mathrm{~Hz}\right)$ indicating an eclipsed (syn) orientation, (dihedral angle $\approx 60^{\circ}, J=2-5 \mathrm{~Hz}$ ). In addition, the coupling constant for $\mathrm{H}-15$ to $\mathrm{H}-14$ is listed as $0.9 \mathrm{~Hz}$ and describes a dihedral angle close to $90^{\circ}$ (dihedral angle $\approx 90^{\circ}, J=0-2 \mathrm{~Hz}$ ). This yields the near anti-orientation of O-3 and O- 6 as seen in the X-ray crystal structure of dihydrotetrodecamycin. In comparison, it is reassuring to note that 13-deoxytetrodecamycin has very similar coupling constants $\left(J_{\mathrm{H} 16, \mathrm{H} 15}=2.9 \mathrm{~Hz}\right)$ and $\left(J_{\mathrm{H} 15, \mathrm{H} 14}=1.8 \mathrm{~Hz}\right)$ representing dihedral angles of $\sim 60^{\circ}, \sim 90^{\circ}$, respectively, for each of these proton pairs and an eclipsed (syn) orientation, offering a relative configuration identical to tetrodecamycin/dihydrotetrodecamycin as represented in Figure 1. The most difficult structural elucidation aspect of this molecule was the relative configuration of $\mathrm{H}-13$, whether it possessed an anti or syn relationship to $\mathrm{H}-8$, representing either a trans-fused or cis-fused decalin ring system. A complicating factor is the fact that the chemical shifts of $\mathrm{H}-13$ and $\mathrm{H}-8$ coalesce in a range
Table 4 Antibacterial activity of 13-deoxytetrodecamycin against Gram-positive bacteria

\begin{tabular}{|c|c|c|c|}
\hline \multirow[b]{2}{*}{ Test organism } & \multicolumn{3}{|c|}{$\operatorname{MIC}\left(\mu \mathrm{g} \mathrm{ml^{-1 } )}\right.$} \\
\hline & deoxytetrodecamycin & Ampicillin & Vancomycin \\
\hline Bacillus subtilis 168 & 2 & $<1$ & $<1$ \\
\hline Micrococcus luteus & 8 & $<1$ & $<1$ \\
\hline $\begin{array}{l}\text { Staphylococcus aureus ATCC } \\
29213\end{array}$ & 8 & $<1$ & 2 \\
\hline S. aureus ATCC BAA-41 & 1 & 16 & 2 \\
\hline S. aureus ATCC BAA-44 & 8 & 32 & 2 \\
\hline S. saprophyticus ATCC 15305 & 8 & $<1$ & 2 \\
\hline S. epidermidis ATCC 12228 & 8 & $<1$ & 2 \\
\hline $\begin{array}{l}\text { Enterococcus faecalis ATCC } \\
29212\end{array}$ & 4 & $<1$ & 2 \\
\hline Escherichia coli ATCC 25922 & $>64$ & 16 & $>64$ \\
\hline
\end{tabular}

just above $1.2 \mathrm{ppm}$, near a multitude of other proton chemical shifts. This makes the direct determination of the coupling constant between H-13 and H-8 nearly impossible, and short of an x-ray crystal structure, alternate methods would be needed to determine the relative stereochemistry. The coupling constant between $\mathrm{H}-14$ and $\mathrm{H}-13$ has been determined to be $4.2 \mathrm{~Hz},\left(J_{\mathrm{H} 14, \mathrm{H} 13}=4.2 \mathrm{~Hz}\right)$ representing a dihedral relationship close to $60^{\circ}$ and an eclipsed orientation between $\mathrm{H}-13$ and $\mathrm{H}-14$. In order to minimize the strain of a transdecalin ring system, it would be expected for the $\mathrm{C} 14-\mathrm{OH}$ group and the $\mathrm{C}-12$ carbon attached to $\mathrm{C}-13$ to adopt an anti orientation, placing $\mathrm{H}-13$ and H-14 in a syn orientation and a dihedral angle close to $60^{\circ}$. By contrast, a cis-decalin orientation would force $\mathrm{C} 14-\mathrm{OH}$ group and the C-12 carbon attached to C-13 to adopt a similar syn orientation, causing $\mathrm{H}-14$ and $\mathrm{H}-13$ to have a very small dihedral angle close to zero and a coupling constant above $7 \mathrm{~Hz}$. As a result, $J_{\mathrm{H} 14, \mathrm{H} 13}=4.2 \mathrm{~Hz}$ denotes a trans-fused decalin system as is shown in Figure 1 and, although not entirely conclusive due to the coalescing chemical shifts of $\mathrm{H}-8$ and $\mathrm{H}-13$, the relative stereochemistry depicted offers an accurate representation of the data.

\section{Antibacterial activity of 13-deoxytetrodecamycin}

To assess the antibacterial activity of pure 13-deoxytetrodecamycin, we determined MICs against a panel of Gram-positive and Gram-negative bacteria (Table 4). We observed potent activity against the Gram-positive organism in the range of 1 to $8 \mu \mathrm{g} \mathrm{ml}^{-1}$ including methicillin-resistant $S$. aureus ATCC BAA-41 and multi drug-resistant S. aureus ATCC BAA-44. Activity of 13-deoxytetrodecamycin against the Gram-negative organism Escherichia coli has been observed at very high concentrations with disk diffusion assays (data not shown).

\section{DISCUSSION}

In this paper we introduced strain WAC04657 and presented the identification, isolation and characterization of the antibiotic 13-deoxytetrodecamycin (Figure 1), a new congener of the tetrodecamycin family. ${ }^{24-26}$ Previously, this family has only been detected in Streptomyces nashvilliensis which, indeed, is related to WAC04657 according to our $16 \mathrm{~S}$ rDNA phylogeny (Figure 2). Of particular interest is the activity against antibiotic-resistant strains of $S$. aureus and other infectious bacteria. 13-Deoxytetrodecamycin exhibited potent activity against $S$. aureus ATCC BAA-44, a strain that the American Type Culture Collection (ATCC) reports is resistant to 
ampicillin, amoxicillin/clavulanic acid, ciprofloxacin, cephalothin, doxycycline, gentamicin, erythromycin, imipenem, methicillin, penicillin, tetracycline, oxacillin, azithromycin, clindamycin, ceftriaxone, rifampin, amikacin, tobramycin and streptomycin. ${ }^{30}$ This suggests possible utility for this molecule in treating infections caused by such highly resistant bacteria. Previous literature demonstrated that the tetrodecamycins can be chemically modified ${ }^{31}$ suggesting the possibility of improving 13-deoxytetrodecamycin's activity further through semi-synthesis. Finally, we note that this compound has limited activity against Gram-negative bacteria. Thus, our observation of WAC04657's activity against Gram-negative bacteria suggests the presence of another antibiotic molecule.

\section{ACKNOWLEDGEMENTS}

We are grateful to Dr Gerry Wright for sharing strains, Dr Kalinka Koteva for advice with compound purification and Thomas Johnson for help measuring optical rotation. This work was supported by grants from the Canadian Institutes for Health Research (MOP-57684) and from Cystic Fibrosis Canada.

1 Schatz, A., Bugle, E. \& Waksman, S. A. Streptomycin, a substance exhibiting antibiotic activity against Gram-positive and Gram-negative Bacteria. Exp. Biol. Med. 55, 66-69 (1944).

2 Baltz, R. H. Marcel Faber Roundtable: Is our antibiotic pipeline unproductive because of starvation, constipation or lack of inspiration? J. Ind. Microbiol. Biotechnol. 33 507-513 (2006)

3 Watve, M. G., Tickoo, R., Jog, M. M. \& Bhole, B. D. How many antibiotics are produced by the genus Streptomyces? Arch. Microbiol. 176, 386-390 (2001).

4 Bentley, S. D. et al. Complete genome sequence of the model actinomycete Streptomyces coelicolor A3(2). Nature 417, 141-147 (2002).

$5 \mathrm{Ikeda}, \mathrm{H}$. et al. Complete genome sequence and comparative analysis of the industrial microorganism Streptomyces avermitilis. Nat. Biotechnol. 21, 526-531 (2003)

6 Ohnishi, Y. et al. Genome sequence of the streptomycin-producing microorganism Streptomyces griseus IFO 13350. J. Bacteriol. 190, 4050-4060 (2008).

7 Nett, M., Ikeda, H. \& Moore, B. S. Genomic basis for natural product biosynthetic diversity in the actinomycetes. Nat. Prod. Rep. 26, 1362-1384 (2009).

8 Barona-Gómez, F., Wong, U., Giannakopulos, A. E., Derrick, P. J. \& Challis, G. L Identification of a cluster of genes that directs desferrioxamine biosynthesis in Streptomyces coelicolor M145. J. Am. Chem. Soc. 126, 16282-16283 (2004).

9 Park, H. M. et al. Genome-based cryptic gene discovery and functional identification of NRPS siderophore peptide in Streptomyces peucetius. Appl. Microbiol. Biotechnol. 97 1213-1222 (2012).

10 Corre, C., Song, L., O'Rourke, S., Chater, K. F. \& Challis, G. L. 2-Alkyl-4hydroxymethylfuran-3-carboxylic acids, antibiotic production inducers discovered by Streptomyces coelicolor genome mining. Proc. Natl. Acad. Sci. USA 105, 17510-17515 (2008)

11 McKenzie, N. L. et al. Induction of antimicrobial activities in heterologous streptomycetes using alleles of the Streptomyces coelicolor gene absA1. J. Antibiot. (Tokyo) 63 177-182 (2010)
12 Gottelt, M., Kol, S., Gomez-Escribano, J. P., Bibb, M. \& Takano, E. Deletion of a regulatory gene within the cpk gene cluster reveals novel antibacterial activity in Streptomyces coelicolor A3(2). Microbiology 156, 2343-2353 (2010).

13 Hosaka, T. et al. Antibacterial discovery in actinomycetes strains with mutations in RNA polymerase or ribosomal protein S12. Nat. Biotechnol. 27, 462-464 (2009).

14 Craney, A., Ahmed, S. \& Nodwell, J. Towards a new science of secondary metabolism. J. Antibiot. (Tokyo) 66, 387-400 (2013).

15 Yoon, V. \& Nodwell, J. R. Activating secondary metabolism with stress and chemicals. J. Ind. Microbiol. Biotechnol. 41, 415-424 (2013).

16 Charlop-Powers, Z. et al. Global biogeographic sampling of bacterial secondary metabolism. Elife 4, e05048 (2015).

17 Fenical, W. \& Jensen, P. R. Developing a new resource for drug discovery: marine actinomycete bacteria. Nat. Chem. Biol. 2, 666-673 (2006).

18 Udwary, D. W. et al. Genome sequencing reveals complex secondary metabolome in the marine actinomycete Salinispora tropica. Proc. Natl. Acad. Sci. USA 104 10376-10381 (2007).

19 Wilson, M. C. et al. An environmental bacterial taxon with a large and distinct metabolic repertoire. Nature 506, 58-62 (2014).

20 Ling, L. L. et al. A new antibiotic kills pathogens without detectable resistance. Nature 517, 455-459 (2015)

$21 \mathrm{King}, \mathrm{A}$. M. et al. Aspergillomarasmine A overcomes metallo- $\beta$-lactamase antibiotic resistance. Nature 510, 503-506 (2014).

22 Thaker, M. N. et al. Identifying producers of antibacterial compounds by screening for antibiotic resistance. Nat. Biotechnol. 31, 922-927 (2013).

23 Kang, H. S. \& Brady, S. F. Arimetamycin A: improving clinically relevant ramilies of natural products through sequence-guided screening of soil metagenomes. Angew. Chem. Int. Ed. 52, 11063-11067 (2013).

24 Tsuchida, T. et al. Tetrodecamycin, a new antimicrobial antibiotic from Streptomyces. J. Antibiot. (Tokyo) 47, 386-388 (1994).

25 Tsuchida, T. et al. Tetrodecamycin and dihydrotetrodecamycin, new antimicrobia antibiotics against Pasteurella piscicida produced by Streptomyces nashvillensis MJ885-mF8. I. Taxonomy, fermentation, isolation, characterization and biological activities. J. Antibiot. (Tokyo) 48, 1104-1109 (1995).

26 Tsuchida, T. et al. Tetrodecamycin and dihydrotetrodecamycin, new antimicrobial antibiotics against Pasteurella piscicida produced by Streptomyces nashvillensis MJ885-mF8. II. Structure determination. J. Antibiot. (Tokyo) 48, 1110-1114 (1995).

27 Kieser, T., Bibb, M. J., Buttner, M. J., Chater, K. F. \& Hopwood, D. A. Practical Streptomyces Genetics, The John Innes Foundation, (2000)

28 Edgar, R. C. MUSCLE: multiple sequence alignment with high accuracy and high throughput. Nucleic Acids Res. 32, 1792-1797 (2004).

29 Tamura, K., Stecher, G., Peterson, D., Filipski, A. \& Kumar, S. MEGA6: Molecular Evolutionary Genetics Analysis Version 6.0. Mol. Biol. Evol. 30, 2725-2729 (2013).

30 ATCC Staphylococcus aureus subsp. aureus Rosenbach (ATCC BAA-44) (2015) http:// atcc.org/Products/All/BAA-44.aspx\#characteristics Accessed 11 April 2015.

31 Tsuchida, T. et al. Derivatives of tetrodecamycin. J. Antibiot. (Tokyo) 48, 1330-1335 (1995)

(2c)(1)(2) This work is licensed under a Creative Commons Attribution-NonCommercial-ShareAlike

International License. The images or other third party material in this article are included in the article's Creative Commons license, unless indicated otherwise in the credit line; if the material is not included under the Creative Commons license, users will need to obtain permission from the license holder to reproduce the material. To view a copy of this license, visit http://creativecommons.org/ licenses/by-nc-sa/4.0/

Supplementary Information accompanies the paper on The Journal of Antibiotics website (http://www.nature.com/ja) 